Brian, P. W., Curtis, P. J., Hemming, H. G., Jefferys, E. G., Unwin, C. H. \& Wright, J. M. (1951). J. gen. Microbiol. 5, 619-632.

\title{
Alternaric Acid; a Biologically Active Metabolic Product of Alternaria solani (Ell. \& Mart.) Jones \& Grout; its Production, Isolation and Antifungal Properties
}

\author{
By P. W. BRIAN, P. J. CURTIS, H. G. HEMMING, \\ E. G. JEFFERYS, C. H. UNWIN AND JOYCE M. WRIGHT \\ Imperial Chemical Industries Ltd., Butterwick Research Laboratories, \\ Welwoyn, Hertfordshire
}

SUMMARY: When Alternaria solani is grown on any one of a variety of defined culture media, an antibiotic metabolic product, alternaric acid, accumulates in the medium. The quantity of alternaric acid produced is directly related to the amount of mycelium formed; good yields of alternaric acid are obtained on any medium which supports good growth. Optimal media contain high concentrations (7.5\% (w/v) or more) of sucrose, which is better than any other carbon source tested. Nitrogen may be supplied as nitrate or casein hydrolysate; ammonia as nitrogen source is equally good when supplied in conjunction with a suitable organic acid, $0.25 \%(w / v)$ acetic acid being particularly favourable.

The antibiotic is isolated from optimal media by extraction with chloroform after adjustment to $\mathrm{pH} \mathrm{3.5}$; the solvent is then evaporated and the residue recrystallized from benzene. Yields of the order of $150 \mathrm{mg}$. $/ \mathrm{l}^{\prime}$ are obtained.

Alternaric acid is not antibacterial. Germination of spores of some fungi (e.g. Absidia glauca, Myrothecium verrucaria) is prevented by $1 \mu \mathrm{g} . / \mathrm{ml}$. or less of alternaric acid. Germination of spores of other fungi (e.g. Botrytis allii) is unaffected by concentrations as high as $100 \mu \mathrm{g}$. $/ \mathrm{ml}$., but extension of the germ-tubes is markedly retarded shortly after germination. This secondary retarding effect may be produced by very low concentrations; $0.01 \mu \mathrm{g} . / \mathrm{ml}$. produced an obvious effect with B. allii.

In a preliminary publication (Brian, Curtis, Hemming, Unwin \& Wright, 1949) a metabolic product of Alternaria solani was described which was both antifungal and phytotoxic. The latter property was of particular interest in so far as it might be concerned in the etiology of plant diseases caused by A. solani. The present account deals with the production and isolation of alternaric acid and with its antifungal properties. Its phytotoxic properties and its possible role in diseases caused by $\boldsymbol{A}$. solani will be reported later.

\section{MATERIAL AND METHODS}

Antagonism in agar culture. Detection of antagonism in agar has been carried out by an improvement of the 'streak-test' previously described (Brian \& Hemming, 1947). Four test organisms are used, three bacteria (Bacterium coli, Salmonella typhi and Staphylococcus aureus) and one yeast-like fungus (Candida albicans). In the improved method these organisms were grown on a semi-solid medium containing $2 \%(\mathrm{w} / \mathrm{v})$ sodium alginate; the cultures of each organism were thoroughly mixed and streaked on the agar plates, on which 
colonies of one or other of the Alternaria strains were already established, by expressing from a sterile hypodermic syringe. This method of streaking is far more rapid than streaking infected broth by means of a loop, and gives more regular streaks. Antagonism in agar to the fungus Botrytis allii has been tested by the 'reversed agar' method of Jefferys (1948).

Assays of antifungal activity. A spore-germination test with conidia of $B$. allii was used for routine assays. The test was set up as previously described (Brian \& Hemming, 1945) but was necessarily read differently. It is shown in this paper that the antifungal substance produced by $A$. solani does not inhibit germination of $\boldsymbol{B}$. allii spores but causes a characteristic stunting of the germ-tubes. Accordingly, the procedure has been to assay a series of twofold dilutions to determine the greatest dilution in which at least $90 \%$ of the germ-tubes do not exceed $200 \mu$. in length; normal germ-tubes under the same conditions are at least $400 \mu$. in length. In the first few dilutions of a series, though percentage germination is not affected or, at most, only slightly decreased, the mean germ-tube length may be no more than $20 \mu$. The antifungal activity determined in this way is presented in this paper as the number of twofold dilutions made before the limiting effect, described above, is reached; in effect, therefore, this 'activity index' is proportional to $\log _{2}$ of the concentration of active material.

Methods of culture. In experiments which did not involve extraction of the alternaric acid produced, cultures were grown on $250 \mathrm{ml}$. lots of medium in 'Glaxo' culture vessels (Clayton, Hems, Robinson, Andrews \& Hunwicke, 1944). Samples of the underlying medium were aseptically withdrawn periodically for assay. In general, six or more cultures were set up on each medium in an experiment, samples from each vessel in each set of six being bulked for assay. At the conclusion of each experiment the mycelium from each set of six vessels was filtered off, dried at $100^{\circ}$ and weighed. Where larger quantities of material were needed, for extraction of alternaric acid, earthenware culture vessels, each containing 0.5-1.0 l., were used. All cultures were grown at $25^{\circ}$. None of the strains of $A$. solani used in this study produced conidia without special treatment; consequently, mycelial inocula have been used.

Origin of cultures. Eleven cultures were studied, but results of five only are reported here in any detail; their provenance is described below:

No. 159. Alternaria sp. (NCTC 1007); originally isolated from rotting canvas by Lorrain Smith, 1921.

No. 407. A. solani (Ell. \& Mart.) Jones \& Grout; strain K 30; obtained from R. V. Tipler, Hawthorndale Laboratories, Jealott's Hill Research Station. This was a subculture from a strain (IBPG 7) isolated from tomato fruit, 1946, at the Imperial Bureau of Plant-breeding and Genetics, Cambridge.

No. 408. A. solani (Ell. \& Mart.) Jones \& Grout; strain K 31; obtained from R. V. Tipler, Hawthorndale Laboratories, Jealott's Hill Research Station. This was a subculture from a strain (IBPG 14) isolated from 
tomato fruit, 1946, at the Imperial Bureau of Plant-breeding and Genetics, Cambridge.

No. 483. A. porri (Ell.) Sacc.; Neergaard's strain from Centraalbureau voor Schimmelcultures, Baarn, Holland.

No. 484. A. porri (Ell.) Sacc. f. sp. solani (E. \& M. pr. sp. Neergaard); Neergaard's strain from Centraalbureau voor Schimmelcultures, Baarn, Holland.

Of these, No. 159 is a saprophytic species quite distinct morphologically from the remainder. The other cultures of $A$. solani and $A$. porri are very similar; Neergaard (1945) has proposed to group $A$. porri, $A$. solani and $A$. dauci in one species as formae speciales of $A$. porri. Of these strains, Nos. 407 and 483 are strongly chromogenic, producing abundant wine-red pigment on Czapek medium.

\section{RESULTS}

\section{Antagonism in agar culture}

In agar streak tests $A$. solani No. 407 showed pronounced antagonism to Staph. aureus and Bact. coli; no other strains showed activity of any kind. All showed activity against $B$. allii in the reversed agar test. Complete lack of activity in agar streak tests has been previously reported for another strain of $A$. solani (Brian \& Hemming, 1947).

On the basis of these results, strain 407 was at first selected for further study, the intention being to isolate the antibacterial substance. Cultures were grown on a number of liquid media and assayed for antibacterial activity (serial dilution assays with Staph. aureus and S. typhi, cylinder plates assays with $B$. subtilis) and antifungal activity. Under these conditions no antibacteriad activity was detected but, even at great dilutions, the culture filtrates produced a characteristic 'stunting' of B. allii germ-tubes. Attention was diverted to isolation of the substance responsible for this effect and a study of the cultural conditions under which it is produced, using the method of assay described in an earlier paragraph.

\section{Comparison of strains in liquid culture}

It now seemed desirable to re-examine all the cultures for production of this factor which caused stunted germ-tubes. Table 1 shows the results of such a comparison. . Cultures were grown on medium $\mathbf{N}(10 \%$ glucose + potassium nitrate + mineral salts $)$ and medium $T(10 \%$ glucose + casein hydrolysate + mineral salts); detailed compositions of these media have been given previously (Brian, Curtis \& Hemming, 1947). All the strains grew more rapidly on medium $\mathbf{T}$ and the activity of culture filtrates was somewhat enhanced in the case of strains 407,408 and 483 . Negligible activity was recorded on both media for strains 484 and 159.

On the basis of this and similar experiments, all of which confirmed the high productivity of strain 408 , that strain was chosen for intensive study. 
Table 1. Antifungal activity in cultures of four strains of Alternaria on two media ( $N$ and $T)$

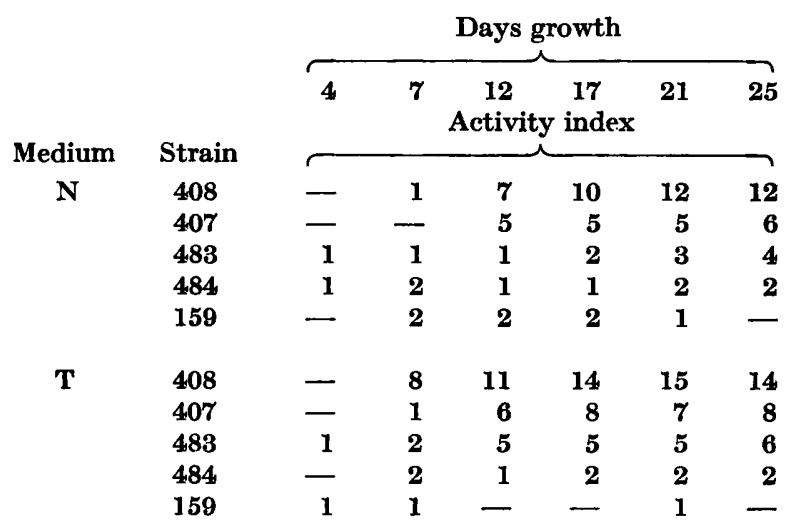

Nevertheless, many experiments described below were also confirmed using strain $\mathbf{4 0 7}$, and, as will be seen, the same active material, alternaric acid, was obtained from both strains.

\section{Relation between medium composition and antifungal activity}

In preliminary experiments it was found that the antifungal substance was freely formed in a simple glucose +nitrate +mineral salts medium (N). The first studies on medium composition described below are concerned with derivatives of this simple medium in which the nature and concentration of the carbon source and the initial $\mathrm{pH}$ of the medium were varied. Subsequently, variation of the nitrogen source and the addition of organic acids were investigated. Strain 408 was used throughout; occasionally strain 407 was included for comparison but results with that strain are not described in detail here.

Glucose concentration. The results of a typical experiment are given in Table 2. It will be seen that both the weight of mycelium produced and the maximum activity titre were directly related to the glucose concentration in the medium. The relation between glucose concentration and $\mathrm{pH}$ drift was less simple. In media with $1.0 \%$ or $2.5 \%$ glucose the $\mathrm{pH}$ rose rapidly in the first twelve days from 4.8 to about $8 \cdot 4$ and thereafter showed relatively little change. In media with higher glucose concentration the rise was less rapid after the eighth day so that on the twelfth day the $\mathrm{pH}$ was around $7 \cdot 8$; thereafter the $\mathrm{pH}$ remained steady or fell slightly in the medium with $10 \%$ and $15 \%$ glucose but fell rapidly in the $5 \%$ glucose medium before reaching a steady level. This anomalous behaviour of media with intermediate glucose concentrations has been observed on several occasions and is seen even more strikingly in Table 3, which describes a similar experiment in Czapek medium, which contains potassium chloride in addition to the salts present in medium $\mathbf{N}$. 
Table 2. Effect of glucose concentration in medium $N$ on antifungal activity, $p H$ drift and final dry reight of mycelium in cultures of

Alternaria solani

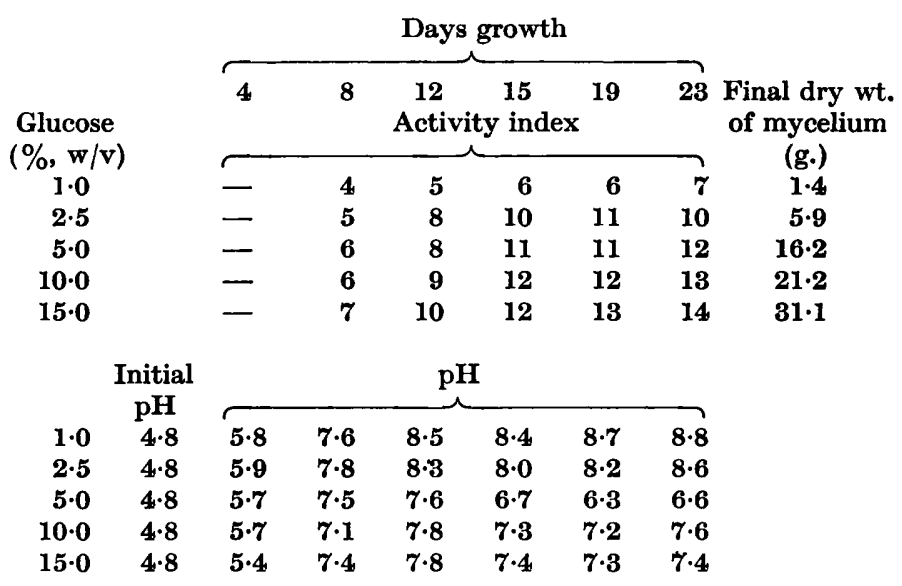

In this experiment (Table 3) the relationship between glucose concentration, antifungal activity and weight of mycelium is the same as in the experiment with medium $\mathrm{N}$ (Table 2) but the $\mathrm{pH}$ drift is surprisingly different. In this case, whereas the media with low glucose $(1 \%$ and $2.5 \%)$ show a $\mathrm{pH}$ rise after a slight initial fall, those with high sugar fall considerably before reaching a steady level, but again the fall is greatest in the medium with $5 \%$ glucose. Both these experiments were repeated with strain 407. Similar results were obtained, though the maximum levels of antifungal activity were much lower.

Table 3. Effect of glucose concentration in Czapek medium on antifungal activity, $p H$ drift and final dry reeight of mycelium in cultures of Alternaria solani

\begin{tabular}{|c|c|c|c|c|c|c|c|c|c|}
\hline & & & & & ys gr & th & & & \\
\hline $\begin{array}{c}\text { Glucose } \\
(\%, w / v)\end{array}$ & & 8 & 11 & & $\begin{array}{r}18 \\
\text { vity }\end{array}$ & $\begin{array}{l}22 \\
\operatorname{dex}\end{array}$ & 26 & 30 & $\begin{array}{l}\text { Final dry wt. } \\
\text { of mycelium }\end{array}$ \\
\hline $1 \cdot 0$ & & - & 1 & 3 & 4 & 7 & 8 & 6 & 3.5 \\
\hline $2 \cdot 5$ & & - & 1 & 6 & 8 & 9 & 10 & $\eta$ & $7 \cdot 8$ \\
\hline $5 \cdot 0$ & & - & 3 & 8 & 9 & 11 & 11 & 11 & $17 \cdot 4$ \\
\hline $10 \cdot 0$ & & 3 & 5 & 8 & 10 & 12 & 11 & 11 & $23 \cdot 3$ \\
\hline $15 \cdot 0$ & & 1 & 5 & 10 & 11 & 12 & 12 & 12 & $28 \cdot 1$ \\
\hline & Initial & & & & pH & & & & \\
\hline $1 \cdot 0$ & 5.6 & $5 \cdot 9$ & $5 \cdot 3$ & $7 \cdot 2$ & $7 \cdot 4$ & 8.0 & $8 \cdot 3$ & $8 \cdot 1$ & \\
\hline $2 \cdot 5$ & 5.5 & 6.0 & 4.7 & $4 \cdot 4$ & $4 \cdot 6$ & $5 \cdot 1$ & $6 \cdot 1$ & $7 \cdot 0$ & \\
\hline $5 \cdot 0$ & $5 \cdot 4$ & 6.0 & 4.5 & $3 \cdot 6$ & $\mathbf{3} \cdot \mathbf{3}$ & 3.5 & $3 \cdot 4$ & $3 \cdot 7$ & \\
\hline $10 \cdot 0$ & $5 \cdot 0$ & $6 \cdot 1$ & 4.9 & 4.4 & $4 \cdot 0$ & $\mathbf{3 . 9}$ & 3.8 & 4.2 & \\
\hline $15 \cdot 0$ & 4.9 & $5 \cdot 9$ & $6 \cdot 4$ & 4.9 & $5 \cdot 0$ & $4 \cdot 6$ & $4 \cdot 4$ & 4.3 & \\
\hline
\end{tabular}


Table 4. Effect of initial $p H$ of medium $N(10 \%, w / v$ glucose $)$ on antifungal activity, $p H$ drift and final dry weight of mycelium in cultures of Alternaria solani

\begin{tabular}{|c|c|c|c|c|c|c|c|c|}
\hline \multirow{4}{*}{$\begin{array}{c}\text { Initial } \\
\mathrm{pH} \\
4 \cdot 0\end{array}$} & \multicolumn{7}{|c|}{ Days growth } & \multirow{3}{*}{$\begin{array}{c}\text { Final dry wt. } \\
\text { of mycelium } \\
\text { (g.) }\end{array}$} \\
\hline & 6 & 9 & 13 & 16 & 20 & 26 & 30 & \\
\hline & \multicolumn{7}{|c|}{ Activity index } & \\
\hline & $\mathbf{3}$ & 8 & 9 & 12 & 14 & 15 & 14 & $29 \cdot 7$ \\
\hline $5 \cdot 0$ & 4 & 9 & 11 & 14 & 14 & 14 & 15 & $29 \cdot 5$ \\
\hline 5.5 & 3 & 7 & 10 & 14 & 15 & 15 & 15 & $30 \cdot 8$ \\
\hline $6 \cdot 6$ & 3 & 7 & 13 & 15 & 15 & 15 & 15 & $29 \cdot 8$ \\
\hline \multirow[t]{2}{*}{$7 \cdot 6$} & - & 一 & 7 & 11 & 14 & 15 & 15 & $24 \cdot 8$ \\
\hline & \multicolumn{7}{|c|}{ pH } & \\
\hline 4.0 & 5.9 & $6 \cdot 6$ & $7 \cdot 2$ & $7 \cdot 4$ & $7 \cdot 8$ & $7 \cdot 6$ & $8 \cdot 0$ & \\
\hline $5 \cdot 0$ & $6 \cdot 2$ & $6 \cdot 6$ & $7 \cdot 1$ & $7 \cdot 5$ & $7 \cdot 4$ & $7 \cdot 3$ & $7 \cdot 7$ & \\
\hline $5 \cdot 5$ & $5 \cdot 8$ & $6 \cdot 4$ & $7 \cdot 3$ & $7 \cdot 6$ & $7 \cdot 9$ & $7 \cdot 7$ & $7 \cdot 9$ & \\
\hline $6 \cdot 6$ & $6 \cdot 7$ & $7 \cdot 1$ & $7 \cdot 7$ & $7 \cdot 7$ & $8 \cdot 1$ & $7 \cdot 8$ & $8 \cdot 2$ & \\
\hline $7 \cdot 6$ & $7 \cdot 3$ & $7 \cdot 2$ & 6.8 & $7 \cdot 0$ & $7 \cdot 3$ & $7 \cdot 2$ & $7 \cdot 4$ & \\
\hline
\end{tabular}

Initial $p H$ of the medium. The results of an experiment where medium $\mathbf{N}$ (10\% glucose) was initially adjusted, with $\mathrm{KOH}$ or $\mathrm{HCl}$, to a range of $\mathrm{pH}$ values between 4.0 and $7 \cdot 6$ are recorded in Table 4 . The $\mathrm{pH}$ of all media followed a similar course after the thirteenth day of fermentation; the final titres of antifungal activity and the dry weight of mycelium formed were

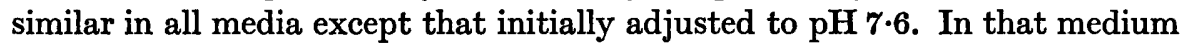
growth was initially slow, development of antifungal activity was correspondingly retarded and the final dry weight of mycelium formed was somewhat less than on the other media. In all subsequent experiments the medium has been initially adjusted to $\mathrm{pH} 5 \cdot 5-6 \cdot 5$.

Table 5. Effect of carbon source $(10 \%, w / v)$ in medium $N$ on antifungal activity, $p H$ drift and final dry weight of mycelium in cultures of Alternaria solani

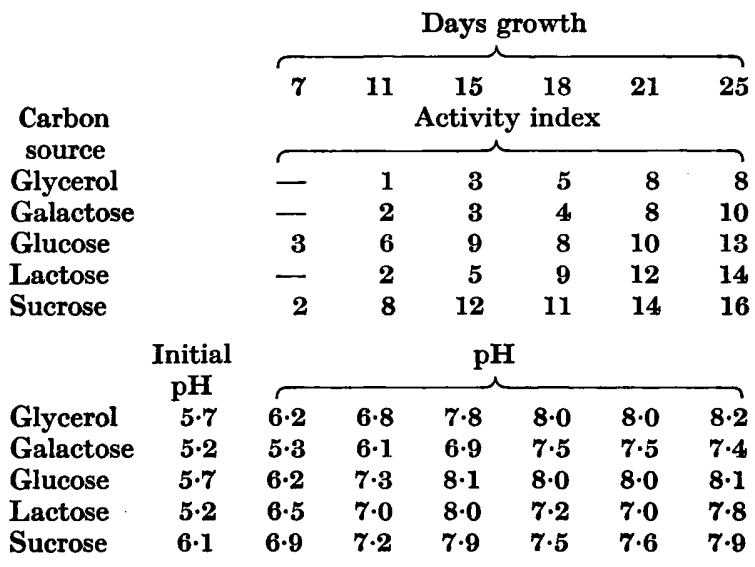

Final dry wt. of mycelium

(g.)

12.4

$13 \cdot 6$

$17 \cdot 9$

$18 \cdot 9$

22.0 
Comparison of carbon sources. Glycerol, galactose, glucose, lactose and sucrose were compared at $10 \%$ concentration in medium $N$ (Table 5). On glycerol and galactose growth was slow and activity titres were correspondingly low. Growth was initially slow on lactose but eventually good mycelial felts were formed and the final activity titres were as good as those on glucose. Titres on the sucrose medium were considerably higher than on glucose, though growth was not markedly different; this result has been frequently confirmed.

Table 6. Effect of sucrose concentration in medium $N$ on antifungal activity, $p H$ drift and final dry roeight of mycelium in cultures of Alternaria solani

\begin{tabular}{|c|c|c|c|c|c|c|c|c|}
\hline \multirow{3}{*}{\multicolumn{2}{|c|}{$\begin{array}{l}\text { Sucrose } \\
(\%, w / v)\end{array}$}} & \multicolumn{6}{|c|}{ Days growth } & \multirow{3}{*}{$\begin{array}{c}\text { Final dry wt. } \\
\text { of mycelium } \\
\text { (g.) }\end{array}$} \\
\hline & & 8 & 12 & 16 & 20 & 26 & 30 & \\
\hline & & \multicolumn{6}{|c|}{ Activity index } & \\
\hline 1.0 & & 1 & 1 & 6 & 7 & 7 & ${ }^{\circ} 4$ & $2 \cdot 9$ \\
\hline $\mathbf{2 \cdot 5}$ & & - & $\mathbf{5}$ & 9 & 10 & 10 & 10 & $10 \cdot 1$ \\
\hline $5 \cdot 0$ & & 1 & 5 & $\mathbf{9}$ & 10 & 11 & 12 & $18 \cdot 5$ \\
\hline $10 \cdot 0$ & & 1 & 7 & 10 & 11 & 12 & 13 & $29 \cdot 6$ \\
\hline $15 \cdot 0$ & & 1 & 9 & 11 & 12 & 13 & 14 & $38 \cdot 0$ \\
\hline \multicolumn{2}{|r|}{$\begin{array}{c}\text { Initia] } \\
\mathbf{p H}\end{array}$} & \multicolumn{6}{|c|}{$\mathrm{pH}$} & \\
\hline 1.0 & $5 \cdot 6$ & $5 \cdot 6$ & $7 \cdot 1$ & $7 \cdot 9$ & $8 \cdot 5$ & $9 \cdot 0$ & $9 \cdot 0$ & \\
\hline $\mathbf{2 \cdot 5}$ & $5 \cdot 4$ & $5 \cdot 7$ & $7 \cdot 3$ & $7 \cdot 4$ & $7 \cdot 5$ & $8 \cdot 0$ & $8 \cdot 4$ & \\
\hline $5 \cdot 0$ & $5 \cdot 3$ & $5 \cdot 2$ & $6 \cdot 8$ & $7 \cdot 1$ & $7 \cdot 0$ & $5 \cdot 6$ & $4 \cdot 6$ & \\
\hline $10 \cdot 0$ & $5 \cdot 4$ & $5 \cdot 8$ & $7 \cdot 0$ & $7 \cdot 6$ & $7 \cdot 5$ & $7 \cdot 4$ & $7 \cdot 1$ & \\
\hline $15 \cdot 0$ & $5 \cdot 0$ & $5 \cdot 7$ & $7 \cdot 3$ & $7 \cdot 3$ & $7 \cdot 3$ & $7 \cdot 5$ & $7 \cdot 6$ & \\
\hline
\end{tabular}

An experiment (Table 6) in which sucrose concentrations were varied between $1 \%$ and $15 \%$ in medium $\mathrm{N}$, showed the same general relationships between sugar concentration, $\mathrm{pH}$ drift, activity titre and weight of mycelium as was found in the experiment with glucose previously described (Table 2). It is interesting to note once more the anomalous $\mathrm{pH}$ drift with $5 \%$ sugar.

Comparison of nitrogen sources. Strain 408 was grown on the simplified medium already described, containing $10 \%$ glucose, nitrogen being supplied in various forms, namely, potassium nitrate $(\mathrm{N})$, ammonium tartrate (AT), ammonium nitrate (AN), ammonium sulphate (AS) and hydrolysed casein (T). The results are presented in Table 7. Growth was very poor on AS and AN, the mycelium being almost entirely submerged. Good felts were produced on all other media, those on $\mathbf{N}$ being particularly good. A similar failure to grow on AS and AN media has been recorded previously (Brian, Curtis \& Hemming, 1947) with the fungus Myrothecium verrucaria (=Metarrhizium glutinosum). Poor growth on these media is associated with a fall to very low $\mathrm{pH}$; the degree of antifungal activity recorded in culture filtrates is remarkably high considering the poor growth. A similar unexpectedly high activity on medium AS, in spite of poor growth, is recorded in Table 8. The GMV 4 
Table 7. Effect of nitrogen source in a $10 \%(w / v)$ glucose medium on antifungal activity, $p H$ drift and final dry weight of mycelium in cultures of Alternaria solani

Nitrogen sources in these media are as follows: $\mathbf{N}$, potassium nitrate; $\mathbf{A N}$, ammonium nitrate; AS, ammonium sulphate; AT, ammonium tartrate; T, hydrolysed casein.

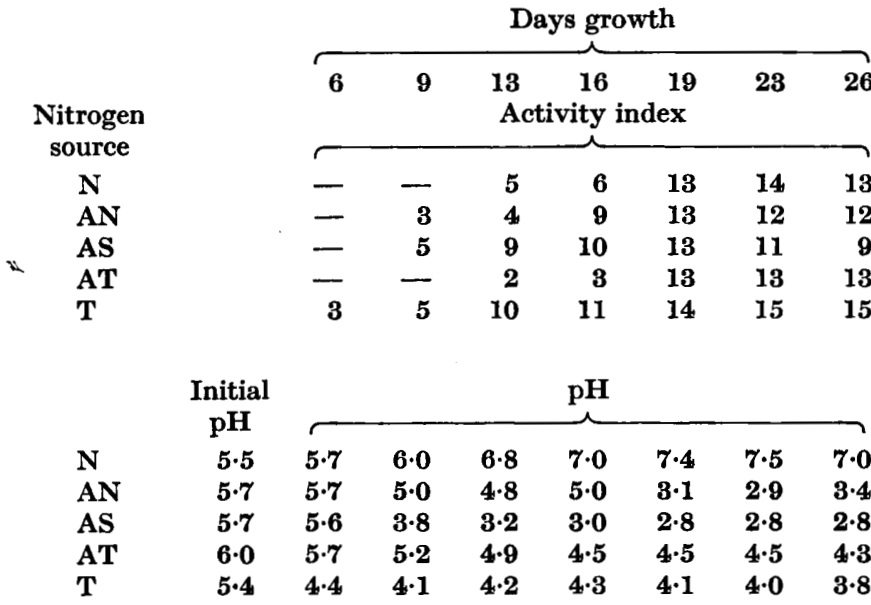

maximum activity reached in both these media after nineteen days was not maintained. High activity developed on media N, AT and T. No one kind of $\mathrm{pH}$ drift is specifically suitable for development of high titres; a steady rise in $\mathrm{pH}$ to about $\mathbf{7 . 5}$ (medium $\mathrm{N}$ ) and a fall to $\mathrm{pH} 3.8$ (medium $\mathrm{T}$ ), were equally suitable.

In this experiment, medium $\mathbf{T}$ gave higher titres than any other medium but even more striking was the far more rapid establishment of a mycelial felt, which would have practical advantages in a large-scale fermentation with this somewhat slow-growing mould.

Effect of organic acid supplements in ammonia media. Brian, Curtis \& Hemming (1947) showed that growth of $M$. verrucaria in ammonia media could be greatly improved by addition of various organic acids to the medium and production of glutinosin was proportionately improved. Similarly addition of various organic acids to medium AS improved growth of $A$. solani and production of the antifungal substance (Table 8).

One effect of the organic acid supplements was to prevent the rapid fall in pH which occurred in unsupplemented medium AS. The effectiveness of the acids varied from that of oxalate, which replaced the steep fall to $\mathrm{pH} 2.5$ by a gradual fall to $\mathrm{pH} \mathrm{4.6}$, to that of acetate which caused a steep rise in $\mathrm{pH}$. In general terms it is true to say that the stimulating effect of the acids on growth was proportional to their effect on $\mathrm{pH}$ drift, acetate causing the greatest growth increases, oxalate the least. The order of antifungal activity of culture filtrates followed the same course, when only those media containing an 
Table 8. Effect of organic acid supplements to medium $A S(10 \%$, $w / v$ glucose) on antifungal activity, $p H$ drift and final dry weight of mycelium in cultures of Alternaria solani

All supplements were added at $1 \%(w / v)$, except acetic acid, which was added at $0.25 \%(\mathrm{w} / \mathrm{v})$, before adjustment of $\mathrm{pH}$ to c. 6 with $\mathrm{KOH}$.

Days growth

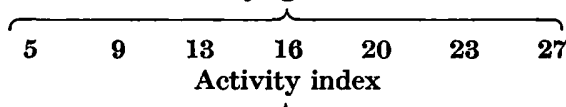

Supplement

Oxalic acid

Malonic acid

Citric acid

Malic acid

Fumaric acid

Tartaric acid

Succinic acid

Acetic acid

$\overline{=}$
$\bar{z}$
$\bar{z}$
$\bar{z}$
$\bar{z}$

Final dry wt. of mycelium

(g.)

3.0

$6 \cdot 3$

$10 \cdot 1$

$12 \cdot 4$

$12 \cdot 9$

$17 \cdot 9$

$18 \cdot 3$

$19 \cdot 6$

$27 \cdot 0$

\begin{tabular}{|c|c|c|c|c|c|c|c|c|}
\hline & Initial & & & & $\mathrm{pH}$ & & & \\
\hline - & 6.0 & $5 \cdot 9$ & $5 \cdot 0$ & $\mathbf{3 \cdot 0}$ & $2 \cdot 9$ & $2 \cdot 9$ & $2 \cdot 7$ & $2 \cdot 6$ \\
\hline Oxalic acid & $5 \cdot 7$ & $5 \cdot 6$ & $5 \cdot 6$ & $5 \cdot 1$ & $5 \cdot 2$ & $4 \cdot 8$ & $4 \cdot 6$ & $4 \cdot 6$ \\
\hline Malonic acid & $5 \cdot 8$ & $5 \cdot 7$ & $5 \cdot 7$ & $5 \cdot 4$ & $\mathbf{5 \cdot 5}$ & $5 \cdot 3$ & $\mathbf{5} \cdot \mathbf{2}$ & 4.9 \\
\hline Citric acid & $5 \cdot 8$ & $5 \cdot 7$ & $5 \cdot 7$ & $5 \cdot 5$ & $5 \cdot 6$ & $5 \cdot 0$ & $5 \cdot 0$ & $5 \cdot 2$ \\
\hline Malic acid & $5 \cdot 7$ & $5 \cdot 6$ & $5 \cdot 6$ & $5 \cdot 9$ & $\mathbf{5 \cdot 9}$ & $5 \cdot 8$ & $5 \cdot 8$ & $5 \cdot 7$ \\
\hline Fumaric acid & $5 \cdot 7$ & $5 \cdot 5$ & $5 \cdot 7$ & $6 \cdot 2$ & $\mathbf{6 \cdot 3}$ & $6 \cdot 1$ & $6 \cdot 5$ & $6 \cdot 5$ \\
\hline Tartaric acid & $6 \cdot 2$ & $6 \cdot 2$ & $5 \cdot 9$ & $5 \cdot 0$ & $5 \cdot 0$ & 4.9 & 4.8 & $5 \cdot 0$ \\
\hline Succinic acid & $5 \cdot 9$ & $5 \cdot 9$ & $5 \cdot 9$ & $6 \cdot 2$ & $6 \cdot 4$ & $6 \cdot 2$ & $6 \cdot 3$ & $6 \cdot 9$ \\
\hline Acetic acid & 6.0 & 6.0 & $5 \cdot 9$ & 6.0 & $7 \cdot 4$ & $7 \cdot 6$ & $8 \cdot 0$ & $7 \cdot 1$ \\
\hline
\end{tabular}

organic acid supplement are considered; the titres for the AS medium unsupplemented were anomalously high, in spite of very poor growth, as has already been recorded.

Further comparison of optimal media. From the series of experiments which have been described it was concluded that high titres of antifungal activity could be obtained on media containing nitrogen as nitrate, as hydrolysed casein or as ammonium sulphate in the presence of acetate, fumarate or succinate. In experiments not detailed here it was established that in each of these types of medium, high sugar concentrations were optimal and that sucrose was superior to glucose. Table 9 shows a comparison of four such media. There was little to choose between the nitrate $(\mathbf{N})$, hydrolysed casein (T) and ammonium sulphate $+0.25 \%$ acetate $(\mathrm{AS}+\mathrm{A})$ media; in other experiments their relative positions might change, though the hydrolysed casein medium was perhaps most reliable owing to the rapidity with which a mycelial felt is formed. The ammonium sulphate $+1 \%$ succinate medium, in this and other experiments, was somewhat less suitable than the other three.

These three optimal media supported heavy growth and consistently high titres were obtained, although the $\mathrm{pH}$ drifts differed considerably. In this 
Table 9. Development of antifungal activity, $p H$ drift and final dry weight of mycelium in cultures of Alternaria solani on four media (10\%, w/v sucrose) differing in nitrogen source

Nitrogen sources in these media are as follows: $N$, potassium nitrate; $T$, hydrolysed casein; AS +A, ammonium sulphate $+0.25 \%(w / v)$ acetic acid; AS $+S$, ammonium sulphate $+1.0 \%(w / v)$ succinic acid.

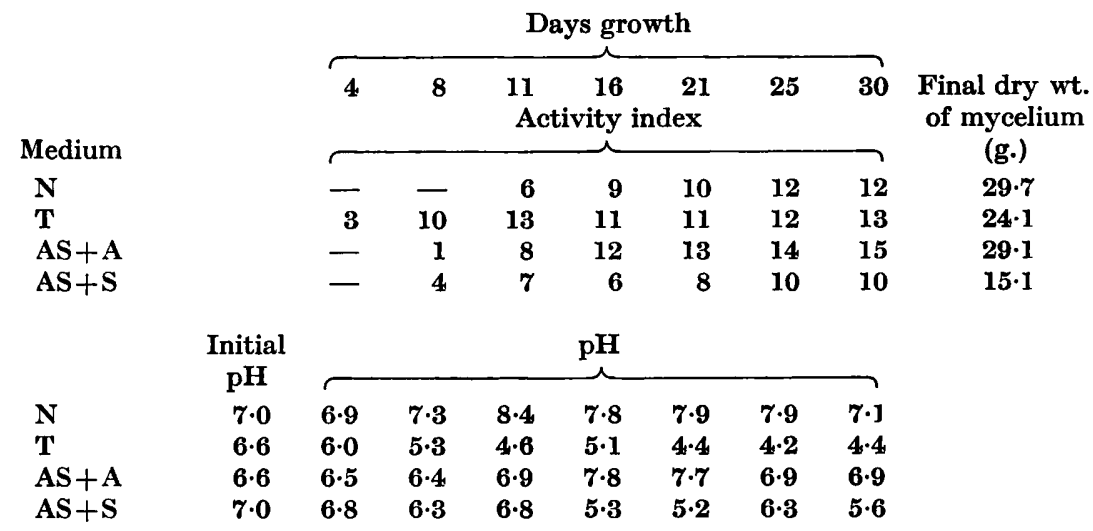

respect the alternaric acid fermentation differs from some others. In the production of viridin by Trichoderma viride (Brian, Curtis, Hemming \& McGowan, 1946), gladiolic acid by Penicillium gladioli (Brian, Curtis \& Hemming, 1948) and gliotoxin by $T$. viride (Brian \& Hemming, 1945), the $\mathrm{pH}$ drift in the culture was found to be a main factor influencing production and accumulation of the antibiotic. In the production of glutinosin by $M$. verrucaria (Brian, Curtis \& Hemming, 1947) and griseofulvin by $P$. janczerskii (Brian, Curtis \& Hemming, 1946), there was no relation between $\mathrm{pH}$ drift and production of the antibiotic, but neither was there any obvious relation between yield of mycelium and yield of antibiotic. In production of alternaric acid by $A$. solani, high titres are almost always correlated with high yield of mycelium. Inspection of the data presented in Tables 2-9 will confirm this, the only significant exceptions being the somewhat high but transient titres recorded on ammonium nitrate (AN) or ammonium sulphate (AS) media in spite of poor growth.

\section{Isolation of alternaric acid}

Isolation of the active material has only been attempted with two strains of A. solani-Nos. 407 and 408. Much the heavier yields have been obtained with $\mathbf{4 0 8}$ and this strain is now used exclusively for production. The substance isolated is the same from both strains.

Development of a method of extraction and purification proceeded simultaneously with the work on development of optimal culture media. In the early stages of the investigation, culture filtrates of low activity only were available. Under those conditions a method of extraction was developed 
which proved to be ineffective for culture filtrates of higher activity; conversely, the method adopted finally for highly-active filtrates had been found ineffective for the earlier batches of low activity. As this relation between isolation technique and concentration of the active material in the fermentation liquor is of some interest, a short account of the development of the extraction methods is given below.

Culture filtrates of three different levels of activity became available during the development process: $(a)$ from strain 407 on glucose + nitrate media, of low activity; (b) from strain 408 on glucose + nitrate media, of moderate activity; (c) from strain 408 on sucrose + nitrate media, of high activity. There were three corresponding stages in the development of the isolation techniques.

Process 1. It was found that the active material could be removed from culture filtrates adjusted to $\mathrm{pH} 3.5$ by extraction with chloroform, benzene or $n$-butanol. Extraction at pH 5.5 or above was inefficient. On evaporation of these solvents, a brown gummy material was produced which could not be recrystallized satisfactorily from petroleum ether, carbon tetrachloride or water; the gum was highly soluble in all other solvents. The chloroform extract was therefore shaken three times with equal volumes of a $\mathrm{pH} 5.5$ buffer and most of the activity was transferred to the buffer. Experience showed that extraction of chloroform extracts with buffer was best done in an atmosphere of nitrogen, otherwise there were considerable losses of activity. When the buffer was then acidified to $\mathrm{pH} \mathbf{3 . 5}$ and extracted with an equal volume of carbon tetrachloride, $75 \%$ of the activity was removed from the buffer. Much coloured impurity was removed by this process; carbon tetrachloride effected more purification than chloroform. On evaporating the carbon tetrachloride a pale yellow gum was obtained. On recrystallization from water, colourless plates were obtained, causing marked stunting of B. allii germ-tubes at $0.1 \mu \mathrm{g}$. $/ \mathrm{ml}$. or even lower concentrations. This substance was found (Brian et al., 1949) to be an optically active dibasic acid and was named alternaric acid. Yields of the order of 1-2 mg./l. were obtained from low-activity culture filtrates in this manner.

Process 2. Using the more active glucose + nitrate culture filtrates from strain 408, which also produced much less pigment, it was found possible to obtain a crystalline product directly from the gummy material obtained by evaporation of the first chloroform extract. It was difficult to remove all brown colour and the procedure, outlined above as process 1, was still used, with the modification of decreasing the volume of the first chloroform extract before re-extracting into buffer. Yields of the order 5-10 mg./l. were obtained.

Process 3. When highly-active culture filtrates from strain 408 on sucrose + nitrate media ( $7.5 \%$ sucrose) became available it was found that the extraction processes described above were unnecessarily complicated. The previously rejected method of evaporation of the first chloroform extract, followed by recrystallization, was again tried and, under these conditions, found successful. The method now adopted is to adjust culture filtrates to $\mathrm{pH} \mathrm{3.5}$, extract twice with 1/10 vol. of chloroform, evaporate the chloroform extract to 
dryness under reduced pressure and recrystallize from benzene. Yields of alternaric acid, under these conditions, are high; the mean yield of ten batches was $140 \mathrm{mg}$./l., the highest yield in the series being $236 \mathrm{mg}$. $/ 1$.

It has been shown earlier that a casein-hydrolysate medium ( $T$ ) is frequently superior to the nitrate medium (N). These two media, both containing $7.5 \%$ sucrose, were compared on three occasions under comparable conditions. The mean yields were: $\mathrm{T}, 167 \mathrm{mg} . / \mathrm{l}$; $\mathrm{N}, 119 \mathrm{mg}$./l. The superiority of medium $\mathrm{T}$ was thus confirmed.

Medium AS, which has earlier been shown to give unexpectedly high assays, gave a mean yield, in comparable experiments, of only $22 \mathrm{mg}$./1. The high titres observed still require explanation.

\section{Antibiotic activity of alternaric acid}

Experiments to determine the stability of aqueous solutions of alternaric acid showed that solutions in Czapek-Dox solution could be boiled for 5 min. in the range $\mathrm{pH} \mathrm{3-7 \cdot 6}$ without loss of activity and could be autoclaved

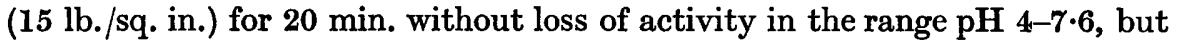
that autoclaving at $\mathrm{pH} 3$ caused a partial loss of activity.

No antibacterial activity has been noticed; the following organisms grew normally in broth containing $100 \mu \mathrm{g}$. alternaric acid $/ \mathrm{ml}$ : Bacillus lactis aerogenes, B. brevis, B. subtilis, Staph. aureus, S. typhi and Bact. coli (two strains).

Antifungal activity was tested by a spore germination test at $\mathrm{pH} \mathbf{3 \cdot 5}$. Table 10 shows the least concentrations $(a)$ inhibiting germination, and $(b)$ causing stunted germ-tubes, of a number of fungi. The extreme specificity should be noted; some fungi, e.g. $M$. verrucaria, are extremely sensitive, germination being completely inhibited by low concentrations of alternaric

Table 10. Antifungal activity of alternaric acid at $p H \mathbf{3 . 5}$

\begin{tabular}{|c|c|c|}
\hline \multirow[b]{2}{*}{ Fungus } & \multicolumn{2}{|c|}{$\begin{array}{l}\text { Least concentration } \\
(\mu \mathrm{g} . / \mathrm{ml} .) \text { of alternaric acid }\end{array}$} \\
\hline & $\begin{array}{l}\text { Inhibiting } \\
\text { germination }\end{array}$ & $\begin{array}{l}\text { Causing } \\
\text { stunting }\end{array}$ \\
\hline Absidia glauca Hagem & 0.8 & $0 \cdot 1$ \\
\hline Aspergillus niger van Tiegh. & $100 \cdot 0$ & $\mathbf{2 5} \cdot 0$ \\
\hline A. tamarii Kita & $\mathbf{5 0} \cdot \mathbf{0}$ & $\mathbf{3} \cdot \mathbf{1}$ \\
\hline Botrytis allii Munn. & $>100 \cdot 0$ & 0.01 \\
\hline Fusarium caeruleum (Lib.) Sacc. & $>100 \cdot 0$ & $100 \cdot 0$ \\
\hline F. graminearum Schwabe & $>100 \cdot 0$ & $\mathbf{2 5} \cdot 0$ \\
\hline $\begin{array}{l}\text { Myrothecium verrucaria (Alb. and Schw.) } \\
\text { Ditm. ex Fries }\end{array}$ & $\mathbf{0} \cdot \mathbf{1}$ & 0.01 \\
\hline Mucor mucedo Bref. & 0.4 & 0.01 \\
\hline Penicillium brevicompactum Dierckx & $>100 \cdot 0$ & $50 \cdot 0$ \\
\hline P. digitatum Sacc. & $>100 \cdot 0$ & $12 \cdot 5$ \\
\hline P. expansum Link & $100 \cdot 0$ & $12 \cdot 5$ \\
\hline P. gladioli Machacek & $50 \cdot 0$ & $25 \cdot 0$ \\
\hline Stemphylium sp. & $25 \cdot 0$ & 0.04 \\
\hline Thamnidium elegans Link & 0.8 & 0.005 \\
\hline
\end{tabular}


acid; others, e.g. Fusarium caeruleum, are very resistant, high concentrations having no noticeable effect; still others, e.g. $B$. allii, show stunted germ-tubes at low concentrations, though much higher concentrations fail to prevent germination.

As in most cases where a toxic agent is a weak acid, alternaric acid is antifungal only in the undissociated state; at $\mathrm{pH} 6.5$ a concentration of 100 $\mu \mathrm{g}$. $/ \mathrm{ml}$. is without visible effect on $B$. allii or $M$. verrucaria.

The stunting effect on fungal hyphae might be produced in several ways, which could not be distinguished by an assay where one observation is made at a fixed time-interval after setting-up the assay. There are three main possibilities: $(a)$ an extension of the latent period before germination commences, followed by normal germination and growth; to produce the observed effects this would mean an extension of the latent period from $1.5 \mathrm{hr}$. to at least $14 \mathrm{hr}$.; $(b)$ a diminution of the rate of hyphal extension after germination and formation of germ-tubes has taken place; $(c)$ a general slowing-down of all the processes of germination and hyphal extension. Several experiments have shown that the second of these possibilities is, in fact, what takes place.

Table 11. Germination and germ-tube extension of Botrytis allii in the presence of alternaric acid, at $25^{\circ}$

\begin{tabular}{|c|c|c|c|c|c|c|}
\hline \multirow[b]{3}{*}{ Time } & \multicolumn{6}{|c|}{ Alternaric acid $(\mu \mathrm{g} . / \mathrm{ml})}$. \\
\hline & \multirow{2}{*}{\multicolumn{3}{|c|}{ Germination (\%) }} & \multirow{2}{*}{\multicolumn{3}{|c|}{ Mean germ-tube length $(\mu$}} \\
\hline & & & & & & \\
\hline 3 & 14 & 23 & 18 & 0.9 & 1.3 & 1.2 \\
\hline $4 \cdot 25$ & 26 & 44 & 20 & $2 \cdot 0$ & 3.8 & $2 \cdot 0$ \\
\hline 5.5 & 39 & $\mathbf{5 3}$ & 37 & 3.0 & $5 \cdot 0$ & $3 \cdot 6$ \\
\hline 7.5 & 63 & $\mathbf{5 3}$ & 43 & $7 \cdot 2$ & 5.7 & 4.4 \\
\hline $10 \cdot 5$ & 90 & 68 & 70 & $54 \cdot 8$ & $11 \cdot 0$ & \\
\hline $12 \cdot 25$ & 100 & 70 & 60 & $82 \cdot 2$ & $10 \cdot 8$ & $9 \cdot 0$ \\
\hline 24 & 100 & 76 & 68 & $462 \cdot 0$ & $12 \cdot 6$ & $10 \cdot 2$ \\
\hline
\end{tabular}

The results of periodical counts of percentage germination and measurements of germ-tube length of $B$. allii spores, in solutions of alternaric acid and in normal nutrient, are shown in Table 11. The final effect of $1 \mu \mathrm{g}$. alternaric acid $/ \mathrm{ml}$., after $24 \mathrm{hr}$., is to decrease percentage germination by $14 \%$ only but to decrease mean germ-tube length from $462 \mu$. to $12 \cdot 6 \mu$. Using a stronger solution $(10 \mu \mathrm{g} . / \mathrm{ml}$.) the effects are slightly more marked. In spite of this marked final effect, for about 6.5 hr. after setting-up the experiment, or about $5 \mathrm{hr}$. after the commencement of germination, alternaric acid has little or no effect; after that point, while the germ-tubes in the normal medium elongate exponentially at a rapid rate, the increase in length of germ-tubes in alternaric acid is very slow. The stunting of germ-tubes caused by alternaric acid is therefore produced by a decrease in the rate of elongation of the young hyphae which does not take effect until some hours after germination has commenced. The further analysis of this interesting effect will be dealt with in a subsequent publication. 


\section{REFERENCES}

Brian, P. W. \& Hemming, H. G. (1945). Gliotoxin, a fungistatic metabolic product of Trichoderma viride. Ann. appl. Biol. 32, 214.

Brian, P. W. \& Hemming, H. G. (1947). Production of antifungal and antibacterial substances by fungi; preliminary examination of 166 strains of Fungi Imperfecti. J. gen. Microbiol. $1,158$.

Brian, P. W., Curtis, P. J. \& Hemming, H. G. (1946). A substance causing abnormal development of fungal hyphae produced by Penicillium janczersskii Zal. Trans. Brit. mycol. Soc. 29, 173.

Brian, P. W., Curtis, P. J. \& Hemming, H. G. (1947). Glutinosin: a fungistatic metabolic product of the mould Metarrhizium glutinosum S. Pope. Proc. roy. Soc. (B) 135, 106.

Brian, P. W., Curtis, P. J. \& Hemming, H. G. (1948). Gladiolic acid, an antibiotic substance produced by Penicillium gladioli McCull. \& Thom. J. gen. Microbiol. $2,341$.

Brian, P. W., Curtis, P. J., Hemming, H. G. \& McGowan, J. C. (1946). The production of viridin by pigment-forming strains of Trichoderma viride. Ann. appl. Biol. 33, 190.

Brian, P. W., Curtis, P. J., Hemming, H. G., Unwin, C. H. \& Wright, J. M. (1949). Alternaric acid, a biologically active metabolic product of the fungus Alternaria solani. Nature, Lond., 164, 534.

Clayton, J. C., Hems, B. A., Robinson, F. A., Andrews, R. D. \& Hunwicke, R. F. (1944). Preparation of penicillin. Improved method of isolation. Biochem. J. 38,452 .

JEFFERYS, E. G. (1948). A technique for rapid demonstration of the production of antifungal substances by fungi or other micro-organisms. Trans. Brit. mycol. Soc. 31, 246.

NeergaArd, P. (1945). Danish species of Alternaria and Stemphylium. Copenhagen: Einar Munksgaard. 